\title{
Antithromboplastic and thromboplastic activities of fatty acids
}

\author{
W. W. FUllerton, W. A. BOGgust, AND R. A. Q. O'MEARA \\ From the Cancer Research Unit of the Department of Experimental Medicine, Trinity College, at Saint \\ Luke's Hospital, Dublin
}

SYNOPSIS In the course of systematic research into the coagulative properties of cancers, facts of wider implication on the behaviour of fatty acids in relation to clotting have been uncovered. It has been shown that saturated fatty acids of appropriate chain length have a direct inhibitory effect on tissue thromboplastins with an optimum of 14 carbon atoms. Unsaturated fatty acids have a similar, though more marked, inhibitory activity with an optimum chain length of 16 carbon atoms. The inhibitory activity is reduced by combining the acids with human serum albumin. Certain fatty acids when dissolved in human serum albumin form labile thromboplastins with properties corresponding to those found in human cancers and in chorion.

Since the discovery by one of us (O'Meara, 1958) that human cancers produce a very labile, readily diffusible, coagulative factor which leads to the formation of fibrin in advance of the tumours and, in certain circumstances, within them, a systematic programme of investigation has proceeded in this department to elucidate the nature and mode of action of the factor concerned. As part of this programme we have been led to consider with special care the relationship of fatty acids to fibrin formation induced by tissue factors, and here record some new observations on their behaviour.

That fatty acids may promote clotting of plasma or blood when introduced into platelet-rich noncontact plasma or blood during studies of the intrinsic clotting mechanism is well known. Poole (1955) studied a series of acids in these circumstances and found stearic acid particularly active in promoting clotting. Nossel (1964) related the action of the fatty acids so introduced to activation of the contact factors in blood and plasma, and in his book reference to many aspects of such work may be found. We confirmed the findings of these authors at an early stage of the present work.

In the fields of general pathology and clinical medicine, fatty acids have attracted attention in relation to cardiovascular disease and thrombosis. Their relationship on the one hand to increased coagulability and thromboplasticity of the blood following ingestion of fat (Fullerton, Davie, and Received for publication 24 February 1967.
Anastasopoulos, 1953; Vavř́k, 1963) or their influence on platelet adhesiveness in similar circumstances (Owren, Hellem, and Ödegaard, 1964) have been the subject of much investigation and have led to extensive clinical trials in which regulation of fat intake, both qualitatively and quantitatively, has been used in attempts to lessen the incidence of vascular thrombosis and vascular disease.

Since our chief interest has been the mechanism of fibrin formation in lymph, through the agency of tissue factors, the test system used in the work recorded here consisted of platelet-poor, fully contacted, citrated plasma which, for purposes of clotting studies, is recalcified in a conventional fashion at the time of test. The addition to such a 웅 system of simple tumour or chorion extracts in water $I$ or saline, of diluted tumour or chorion homogenates, thromboplastic fractions isolated from these by N column chromatography using D.E.A.E.-cellulose (Boggust, O'Brien, O'Meara, and Thornes, 1963) or by Sephadex G.200 gel filtration (Boggust and $\omega$ O'Meara, 1966), microsomes isolated from chorion (Clarke, 1965; Clarke and O'Meara, 1966), or of $\bullet$ conventional human, bovine, or rabbit brain throm- $\Phi$ boplastin, shortens the recalcification clotting time. $\stackrel{?}{?}$

We have now discovered that the clot-promoting activity of each of these tissue thromboplastins is retarded or completely inhibited in the presence of certain long-chain fatty acids which neither $\mathbb{D}$ accelerate nor retard clot formation in the test $\bar{Q}$ plasma alone. 


\section{EXPERIMENTAL}

For quantitative survey of the inhibitory effect of the fatty acids, all reagents were standardized. Standard chorion extract was used as thromboplastin in the experiments here recorded unless otherwise indicated. It was prepared in bulk by simple aqueous extraction of coarsely cut chorion in the cold. The extract was then freeze-dried to give a fine powder. A large volume of a $1 \%$ solution of the powder in saline was prepared, dispensed in small volumes, frozen, and stored at $-25^{\circ} \mathrm{C}$. In these conditions it retains its thromboplastic activity for long periods but must not be re-frozen after thawing. For use in the tests it was diluted so as to coagulate the recalcified plasma test system in the range 125-127-130 seconds. The relationship between the concentration of chorion extract and clotting activity in the test system was established by preparing a standard curve relating clotting times to serial dilutions of the $1 \%$ chorion extract solution over the range 50-to-200 seconds. The curve of this relationship with the relevant part, giving a clotting time of 127, marked on the steep slope is shown in Figure 1. To test for inhibition, $0.4 \mathrm{ml}$. of the thromboplastin solution at $37^{\circ} \mathrm{C}$., mixed with $0.2 \mathrm{ml}$. of the test solution or solvent control, was incubated at $37^{\circ} \mathrm{C}$. Equal volumes of the incubated mixture, of citrated platelet-poor plasma, warmed to $37^{\circ} \mathrm{C}$. for not more than two minutes, and of $\mathrm{M} / 40 \mathrm{CaCl}_{2}$ solution at $37^{\circ} \mathrm{C}$. in saline $(0 \cdot 1 \mathrm{ml}$. of each) were mixed and tested for clotting time at $37^{\circ} \mathrm{C}$.

With the test system described, it was found that the addition of fatty acids inhibitory of tissue thromboplastin to the chorion extract led to progressive inactivation of its thromboplastic activity on incubation at $37^{\circ} \mathrm{C}$. Depending upon the concentrations of thromboplastin and of the inhibitory acid used and its inherent inhibitory capacity, maximum inhibition was achieved in from 15 to 30 minutes' incubation at $37^{\circ} \mathrm{C}$., as shown in Table I.

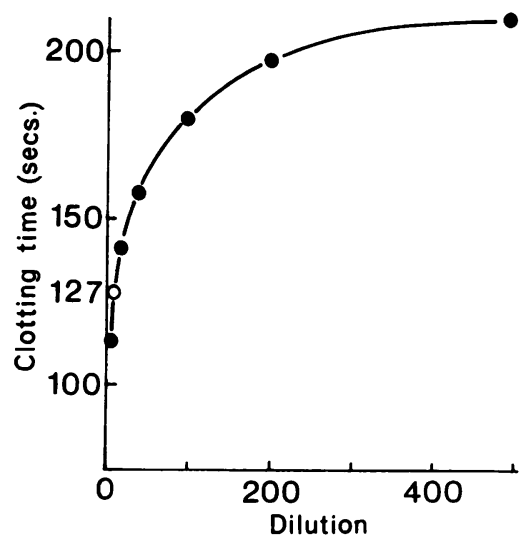

FIG. 1. Relationship between chorion extract concentration and clotting times in platelet-poor plasma. Standard clotting time for extract concentration used in all tests marked at 127 seconds.
TABLE I

PROGRESSIVE INHIBITION OF THROMBOPLASTIN BY FATTY ACIDS AT $37^{\circ} \mathrm{C}$.

\begin{tabular}{lll} 
Test Mixtures and Controls & $\begin{array}{l}\text { Incubation Times } \\
(\text { min.) }\end{array}$ & $\begin{array}{l}\text { Clotting Times } \\
(\text { sec. })\end{array}$ \\
\hline Thromboplastin + myristic & 0 & 122 \\
acid 1/10,000 & 5 & 166 \\
& 10 & 180 \\
& 20 & 197 \\
Thromboplastin + linoleic & 30 & 210 \\
acid 1/10,000 & 5 & 126 \\
& 10 & 175 \\
& 20 & 186 \\
Thromboplastin + saline & 30 & 210 \\
Fatty acid + saline & 30 & 210 \\
Saline & 30 & 120 \\
& 30 & 210
\end{tabular}

It was thus established that inhibition of thromboplastic activity by the fatty acids followed the usual pattern for chemical or physicochemical interaction; and in subsequent experiments, 30 minutes was adopted as the standard incubation time for all test mixtures and controls before clotting tests.

To prepare and maintain solutions of fatty acids at different dilutions in physiological saline at $p \mathrm{H} \mathrm{7.0}$ for test purposes, use was made of Triton Q.S.15, at a concentration of $0.1 \%$. This Triton is amphoteric and at the concentration used did not influence the clotting tests and plasma controls, as the quaternary ammonium cationic type of Tritons (such as cetrimide), are known to do. Controls to exclude its participation were set up with the tests. Incorporation of the fatty acid and Triton into the test solutions was accomplished as follows:

Equal weights of the fatty acid and of the Triton Q.S.15 were melted together in a water or oil bath at a suitably elevated temperature, dissolved in hot saline, adjusted to $p \mathbf{H} 7 \cdot 0$, and diluted to give solutions of $0 \cdot 1 \%(1 / 1,000)$ of each component. Further dilutions at $1 / 10,000,1 / 20,000$, and $1 / 40,000$ of the acid were made in saline containing $0.1 \%$ of the Triton. The stable opalescent solutions thus obtained could be kept without change in their properties for several days at $60^{\circ} \mathrm{C}$.

In the assessment of inhibitory activity the standard curve (Fig. 1) was used to determine percentage loss of thromboplastic activity in each test, varying from 0 to $100 \%$ depending upon the acid used and its concentration and hence, the percentage inhibition. By way of illustration, the results of a typical experiment are shown in Table II.

The plasma used in the clotting tests was obtained from citrated human blood taken into polythene bags or siliconed containers and centrifuged in siliconed tubes to remove cells and platelets. The platelet-poor supernatant plasma was stored at $-25^{\circ} \mathrm{C}$. in ordinary glass containers before use. At this temperature its clotting properties were maintained unaltered for the duration of the tests.

\section{RESULTS}

It was found that the antithromboplastic activity 
TABLE II

TYPICAL EXPERIMENTAL RESULT

\begin{tabular}{|c|c|c|c|}
\hline Test Mixtures and Controls & $\begin{array}{l}\text { Clotting T } \\
\text { (sec.) }\end{array}$ & Times & $\begin{array}{l}\text { Percentage } \\
\text { Inhibition }\end{array}$ \\
\hline Thromboplastin in saline & 127 & & $\mathbf{0}$ \\
\hline $\begin{array}{l}\text { Thromboplastin + Triton } \\
\text { in saline }\end{array}$ & 127 & & 0 \\
\hline $\begin{array}{l}\text { Thromboplastin }+ \text { myristic } \\
\text { acid } 1 / 10,000\end{array}$ & 210 & & 98 \\
\hline $\begin{array}{l}\text { Thromboplastin }+ \text { myristic } \\
\text { acid } 1 / 40,000\end{array}$ & $140-144$ & & 45 \\
\hline $\begin{array}{l}\text { Thromboplastin + linoleic } \\
\text { acid } 1 / 10,000\end{array}$ & 210 & & 98 \\
\hline $\begin{array}{l}\text { Thromboplastin + linoleic } \\
\text { acid } 1 / 40,000\end{array}$ & $148-150$ & & 66 \\
\hline Plasma + saline & 212ך & & - \\
\hline Plasma + Triton in saline & 212 & & - \\
\hline $\begin{array}{l}\text { Plasma + myristic acid } \\
1 / 10,000\end{array}$ & $212\}$ & $210-215$ & 5 \\
\hline $\begin{array}{l}\text { Plasma + linoleic acid } \\
1 / 10,000\end{array}$ & $212 \mathrm{~J}$ & & - \\
\hline
\end{tabular}

of fatty acids is a property of the aliphatic acids themselves, since any substitution by esterification, by internal hydroxylation, or by replacement of the carboxyl group - $\mathrm{COOH}$ by primary alcohol $-\mathrm{CH}_{2} \mathrm{OH}$, led to complete or almost complete inactivation as shown in Table V. The antithromboplastic activity is also related to both chain length and to the degree of saturation. Both the saturated and unsaturated acids show an optimum chain length, 14 carbon atoms for the saturated and 16 for the unsaturated, the unsaturated acids at their optimum giving considerably more inhibition than the saturated. The configuration of the unsaturated acids, whether cis- or trans-, does not appear to influence their inhibitory properties. The inhibitory activities of the saturated fatty acids are set out in Table III and those of the unsaturated in Table IV. The concentrations of fatty acids given are those

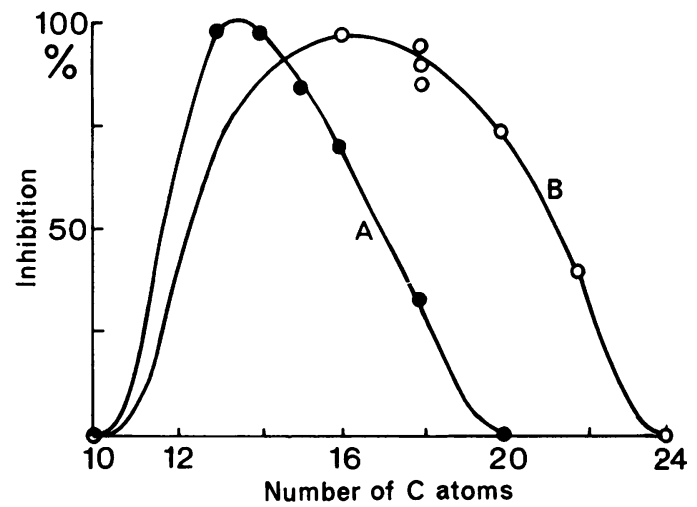

FIG. 2. Relationship between inhibitory activity and chain length is shown graphically for $(A)$ saturated fatty acids at a concentration of 1/10,000 and $(B)$ for the unsaturated acids at a concentration of 1/20,000.
TABLE III

SATURATED FATTY ACIDS

Acid Chain Length Percentage Inhibition at Different (C atoms)

Dilutions

$1 / 1,000 \quad 1 / 10,000 \quad 1 / 20,000 \quad 1 / 40,000$

\begin{tabular}{lrrrrr}
\hline Caprylic & 8 & 0 & 0 & - & - \\
Capric & 10 & 0 & 0 & - & - \\
Tridecanoic & 13 & 98 & 98 & 80 & 40 \\
Myristic & 14 & 98 & 98 & 86 & 45 \\
Pentadecanoic & 15 & 95 & 86 & 45 & 33 \\
Palmitic & 16 & 90 & 71 & 20 & - \\
Stearic & 18 & 71 & 33 & 0 & - \\
Arachidic & 20 & 1 & 0 & - & - \\
Heneicosanoic & 21 & 1 & 0 & - & - \\
Behenic & 22 & 0 & 0 & - & - \\
Lignoceric & 24 & 0 & 0 & - & - \\
Cerotic & 26 & 0 & 0 & - & -
\end{tabular}

${ }^{1}$ Slight thromboplastic activity observed

TABLE IV

UNSATURATED FATTY ACIDS

Acid Chain Length Percentage Inhibition at Different \begin{tabular}{ll} 
(C atoms) Dilutions \\
\hline
\end{tabular}

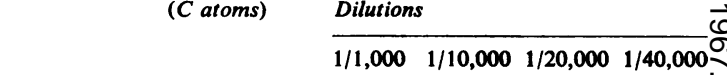

\begin{tabular}{|c|c|c|c|c|c|}
\hline Dec-2-enoic & 10 & $\mathbf{0}$ & $\mathbf{0}$ & 0 & - \\
\hline Palmitoleic & 16 & $\begin{array}{l}98 \\
98\end{array}$ & 98 & 98 & 75 \\
\hline Palmitelaidic & & 98 & 98 & 98 & 75 \\
\hline $\begin{array}{l}\text { Petroselinic } \\
\text { Linoleic }\end{array}$ & 18 & $\begin{array}{l}98 \\
98\end{array}$ & $\begin{array}{l}98 \\
98\end{array}$ & $\begin{array}{l}95 \\
86\end{array}$ & $\begin{array}{l}75 \\
66\end{array}$ \\
\hline Linolenic & & 98 & 98 & 86 & 66 \\
\hline Oleic $^{1}$ & & 98 & 94 & 90 & 66 \\
\hline Elaidic & & 98 & 94 & 90 & 66 \\
\hline Vaccenic (trans) & & 98 & 94 & 90 & 66 \\
\hline $\begin{array}{l}\text { Eicosapen- } \\
\text { taenoic }\end{array}$ & 20 & 98 & 91 & 75 & 55 \\
\hline$\Delta^{11}$-eicosaenoic & & 98 & 91 & 75 & 55 \\
\hline $\begin{array}{l}\text { Docosahex- } \\
\text { aenoic }^{1}\end{array}$ & 22 & 98 & 91 & 66 & - \\
\hline Erucic ${ }^{2}$ & & 98 & 75 & 40 & 15 \\
\hline Brassidic $^{1}$ & & 98 & 75 & 40 & 15 \\
\hline Nervonic & 24 & 71 & 33 & 0 & - \\
\hline
\end{tabular}

'Slightly inhibits plasma clotting

TABLE V

RELATED COMPOUNDS

Chain Length Hydroxyacids, Alcohols, and Esters Percentage $\mathcal{\circ}$

(C atoms) Inhibition at

(C atoms)

9:10:16 Trihydroxypalmitic acid $1 / 10,000$

12-Hydroxystearic acid

2-Hydroxymyristic acid

12-Hydroxy-9-octadecenoic acid

(Ricinoleic)

Oleyl alcohol

Lauryl alcohol

Methyl laurate

Methyl myristate

Methyl palmitate

Methyl linoleate

Methyl eicosapentaenate

Methyl arachidonate

Glyceryl trioleate

Glyceryl trilaurate 
of the solutions of the acids used for the tests, not the final dilutions when in contact with the thromboplastins, which were threetimes higher. The relationship between inhibitory activity and chain length is shown graphically for saturated fatty acids at a concentration of $1 / 10,000$ in Fig. 2 (curve A) and for the unsaturated acids at a concentration of $1 / 20,000$ in Fig. 2 (curve B).

Four fatty acids of high and low antithromboplastic activity, two saturated and two unsaturated, were assayed in the usual dilutions against a representative group of tissue thromboplastins. The acids used were myristic, stearic, petroselinic, and nervonic. The thromboplastins in saline solutions or suspensions of equal acceleratory capacity for the platelet-poor plasma test system were Difco rabbit brain thromboplastin, chorion extract peak 1 from Sephadex G.200, chorion microsomes, saline extract of chorion, and chorion extracted with $0.2 \%$ purified human serum albumin in saline. The results are given in Table VI and show that all the thromboplastins are inhibited by the fatty acids and that the inhibitory effect is reduced by the presence of albumin. It will be noted that nervonic acid at the higher dilutions enhances the thromboplastic activity of chorion extract for plasma in the presence of added human serum albumin. Thus, it exhibits antithromboplastic activity against all the tissue thromboplastins, but in high dilution becomes thromboplastic in the presence of albumin. Nervonic acid is not peculiar in this respect, since we have found that some fatty acids when taken into solution in human serum albumin develop thromboplastic activity, which shows varying degrees of lability at $37^{\circ} \mathrm{C}$. When investigating the behaviour of these acids, stearic acid was tested with human serum albumin in the same fashion without revealing thromboplastic activity. Tested against tissue thromboplastin, it is inhibitory. In these respects its behaviour is in sharp contrast to the marked activity it exhibits in promoting clotting in non-contact platelet-rich plasma or blood. By way of illustration, the results obtained by combining arachidic acid and stearic acid respectively with electrophoretically prepared crystalline human serum albumin are shown in Table VII.

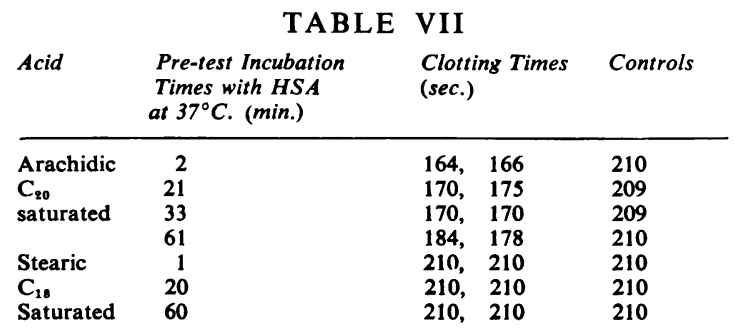

The fatty acid $0.05 \%$ and albumin $1.9 \%$ were taken into solution in saline with Triton Q.S. 15 as before and allowed to interact at $37^{\circ} \mathrm{C}$., the mixtures being tested at intervals for thromboplasticity by addition to platelet-poor plasma with recalcification. It will be seen from the table that arachidic acid forms a labile thromboplastin with albumin, reaching its maximum after about two minutes and thereafter begins to lose its activity on further incubation at $37^{\circ} \mathrm{C}$. This thromboplastin is completely thermolabile at $60^{\circ} \mathrm{C}$. in 30 minutes. Stearic acid fails to form a thromboplastin under identical conditions. Controls with albumin but no fatty acid show no thromboplastic effect; neither do controls with fatty acid alone. These results have been confirmed many times, both with and without incorporation of Triton Q.S.15 in the mixtures.

TABLE VI

PERCENTAGE INHIBITIONS OF DIFFERENT THROMBOPLASTINS BY SELECTED FATTY ACIDS

\begin{tabular}{|c|c|c|c|c|c|c|}
\hline Acid & Dilution & $\begin{array}{l}\text { Brain Thrombo- } \\
\text { plastin (Difco) }\end{array}$ & $\begin{array}{l}\text { Chorion Extract } \\
\text { Peak I Sephadex } \\
\text { G.200 }\end{array}$ & $\begin{array}{l}\text { Chorion } \\
\text { Microsomes }\end{array}$ & Chorion Extract & $\begin{array}{l}\text { Chorion Extract } \\
+H S A\end{array}$ \\
\hline Myristic $C_{14}$ & $1 / 1,000$ & 93 & 95 & 95 & 98 & 90 \\
\hline \multirow[t]{3}{*}{ Saturated } & $1 / 10,000$ & 66 & 75 & 75 & 98 & 33 \\
\hline & $1 / 20,000$ & 0 & 33 & 50 & 86 & 0 \\
\hline & $1 / 40,000$ & 0 & 0 & 0 & 45 & 0 \\
\hline Stearic $C_{18}$ & $1 / 1,000$ & 75 & 33 & 60 & 71 & 50 \\
\hline \multirow[t]{2}{*}{ Saturated } & $1 / 10,000$ & 0 & 0 & $\mathbf{0}$ & 33 & 33 \\
\hline & $1 / 20,000$ & 0 & o & 0 & 0 & 0 \\
\hline Petroselinic $C_{18}$ & $1 / 1,000$ & 100 & 95 & 100 & 98 & 98 \\
\hline \multirow[t]{3}{*}{ Mono-unsaturated } & $1 / 10,000$ & 93 & 75 & 83 & 98 & 33 \\
\hline & $1 / 20,000$ & 75 & 66 & 55 & 95 & 0 \\
\hline & $1 / 40,000$ & 50 & 0 & 0 & 75 & $\mathbf{0}$ \\
\hline Nervonic $C_{24}$ & $1 / 1,000$ & 100 & 91 & 100 & 71 & 50 \\
\hline \multirow[t]{3}{*}{ Mono-unsaturated } & $1 / 10,000$ & 93 & 60 & 82 & 33 & 0 \\
\hline & $1 / 20,000$ & 75 & 0 & 55 & 0 & 1 \\
\hline & $1 / 40,000$ & 50 & 0 & 0 & 0 & 1 \\
\hline
\end{tabular}




\section{DISCUSSION}

Our studies on the thromboplastic activity of tissue extracts, the isolated soluble thromboplastins and the cell structures (endoplasmic reticulum) from which the thromboplastic activity derives, as well as their chemical and physical properties determined by column chromatography and conventional analytical procedures, have suggested to us that the fatty acids play an important part in the regulation of clotting initiated by tissue thromboplastins. Depending upon circumstance, some of these acids may exert either a directly inhibitory effect on the thromboplastic activity of tissue extracts; or, alternatively, by combining with albumin and possibly other proteins, they become thromboplastins. The formation of thromboplastins in this fashion could be important in relation to increase in the thromboplasticity of blood following ingestion of fat. From the experiments recorded here it is apparent that these effects of fatty acids will be found to be related to their chemical structure, physicochemical state, and, in particular, to their ability to form complexes with proteins, and to the character of the complexes so formed.

There is a sharp contrast between the behaviour of fatty acids in relation to clotting initiated by tissue thromboplastin and by plasma factors. For example, stearic acid is probably the most active of the fatty acids in promoting clotting of plateletrich non-contact plasma, whereas we have not found that it forms a thromboplastin when taken into solution in albumin and it has a slight inhibitory action against tissue thromboplastin. Many fatty acids have no demonstrable activity in connexion with the clotting mechanism, but one must seriously consider whether those which have may not constitute an integral part of the clotting mechanism and its regulation, at least so far as the initial stages of the extrinsic clotting system are concerned.
Our experience with these acids shows that knowledge of their behaviour, especially when combined with proteins, deserves full investigation by chemical, biochemical, biophysical, and biological methods so that the whole relationship of fatty acids to clotting may be placed on a less empirical basis than at present. Part of our research work is directed towards this end in an effort to determine these relationships exactly: primarily because of their importance in cancer, but nevertheless recognizing $\vec{\circ}$ that they may also be important in thrombosis and cardiovascular disease.

Generous financial assistance from Tenovus is gratefully acknowledged. One of us, W. W. F., holds a Fellowship of the Medical Research Council of Ireland and we are of indebted to the Council for a grant-in-aid to W. A. B. N The blood withdrawn into polythene bags was provided by the National Blood Transfusion Board, to whose director, Dr. O'Riordan, our thanks are extended.

The fatty acids and related compounds used in this $\vec{\bullet}$ investigation were obtained from Sigma, London; of Koch-Light Laboratories, Bucks.; the Mann Research Laboratories, New York; and the Aldrich Chemical Company, Ltd., U.S.A. Human serum albumin was from the Mann Research Laboratories and Triton Q.S.15 from Lennig Chemical Co., London.

\section{REFERENCES}

Boggust, W. A., O'Brien, D. J., O'Meara, R. A. Q., and Thornes, R. D (1963). Irish J. med. Sci., 131.

, and O'Meara, R. A. Q. (1966). Ibid., 11.

Clarke, N. (1965). Nature (Lond.), 205, 608.

- , and O'Meara, R. A. Q. (1966). Brit. J. Haemat., 12, 536.

Fullerton, H. W., Davie, W. J. A., and Anastasopculos, G. (1953). Brit. med. J., 2, 250.

Nossel, H. L. (1964). The Contact Phase of Blood Coagulation. Blackwell, Oxford

O'Meara, R. A. Q. (1958). Irish J. med. Sci., 474.

Owren, P. A., Hellem, A. J., and Odegaard, A. (1964). Lancet, 2, 975.

Poole, J. C. F. (1955). Brit. J. exp. Path., 36, 248.

Vavrik, M. (1963). Lancet, 1, 421. 